\title{
Rhythms of Prediction in South Australian Water Resource Management
}

\author{
STEVE RAYNER \\ James Martin Professor of Science and Civilization, Oxford University, Oxford, United Kingdom, and Australia \\ and New Zealand School of Government-Goyder Institute Visiting Professor in Public Sector Policy and \\ Management, Flinders University, Adelaide, South Australia, Australia
}

(Manuscript received 26 September 2018, in final form 13 December 2018)

\begin{abstract}
In the complex institutional and physical infrastructure nexus of South Australia, weather and climate information is highly valued by freshwater managers and users. But different users focus on very different time scales. Recent changes in water rights and technology, driven by the Millennium Drought, enable agricultural users to focus on real-time monitoring and relatively short-term forecasts (3-5 days ahead). A wide range of users make extensive use of the full 7-day weather forecasts and there is awareness of, but not reliance on, seasonal outlooks. These are widely viewed as providing "background" indications and are seldom directly used in decision-making. While concern about climate change is driving scientific research on downscaling climate impact models for the region, there are different views among decision-makers about the usefulness of these for adaptation. All forms of weather and climate information appear to be best integrated into decision-making when incorporated into sector-specific models and decision-support tools alongside other relevant variables. However, there remains something of a mismatch between scientific aspirations to improve the skill of seasonal and long-term climate forecasting and the temporal rhythms of water-resource decision-making.
\end{abstract}

\section{Introduction}

Often described by interviewees as "the driest state on the driest inhabited continent," South Australian agriculture, human habitation, and its natural environment are highly dependent on weather and climate, which are controlling variables affecting the availability of scarce water resources. Although vast in area, the population is small and concentrated around Adelaide, where most government and research capacity is to be found in close proximity. Hence, the state of South Australia (SA) presents an ideal context in which to explore the role of weather and climate information in the management of urban and agricultural water (Fig. 1). The research set out to identify factors that promote, enable, or constrain the successful use of data and forecasts on various time scales, and the extent to which forecast information quality and/or institutional practices of decision-makers contribute to these forecasts being used or not used.

Earlier studies have shown that agricultural and municipal water managers have not viewed information on short-term climate forecasting, also known as seasonal

Corresponding author: Steve Rayner, steve.rayner@insis.ox. ac.uk outlooks or projections, as particularly useful (Callahan et al. 1999; Easterling and Stern 1999; Rayner et al. 2005). Specifically in Australia, Hayman et al. (2007) found that it was not easily compatible with existing farming practices. In other cases, such information has been seen as benefitting particular users at the expense of others (Broad 2002; Lemos et al. 2002), or contributing to undesired outcomes (Broad 2002; Pielke 1999). In all cases, the use and value of these forecasts depends on the types of institutions that are generating the information and making the decisions (Cash et al. 2003), and research repeatedly shows that seasonal forecasts do not focus sufficiently on specific users' needs to be fully integrated into their decisionmaking processes (Ziervogel et al. 2010; Kirchhoff 2013).

The research reported here was specifically conceived as an expansion of earlier work on the use and nonuse of short-term climate forecasts in the United States (Rayner et al. 2005). This found that, while short-term climate forecasting promised improved hydrologic management, water-resource managers in the United States were reluctant to incorporate them in decision-making. While managers usually cited "poor reliability" of the forecasts as the reason for this, they were seldom able to demonstrate knowledge of the performance of forecasts or to articulate the level of 


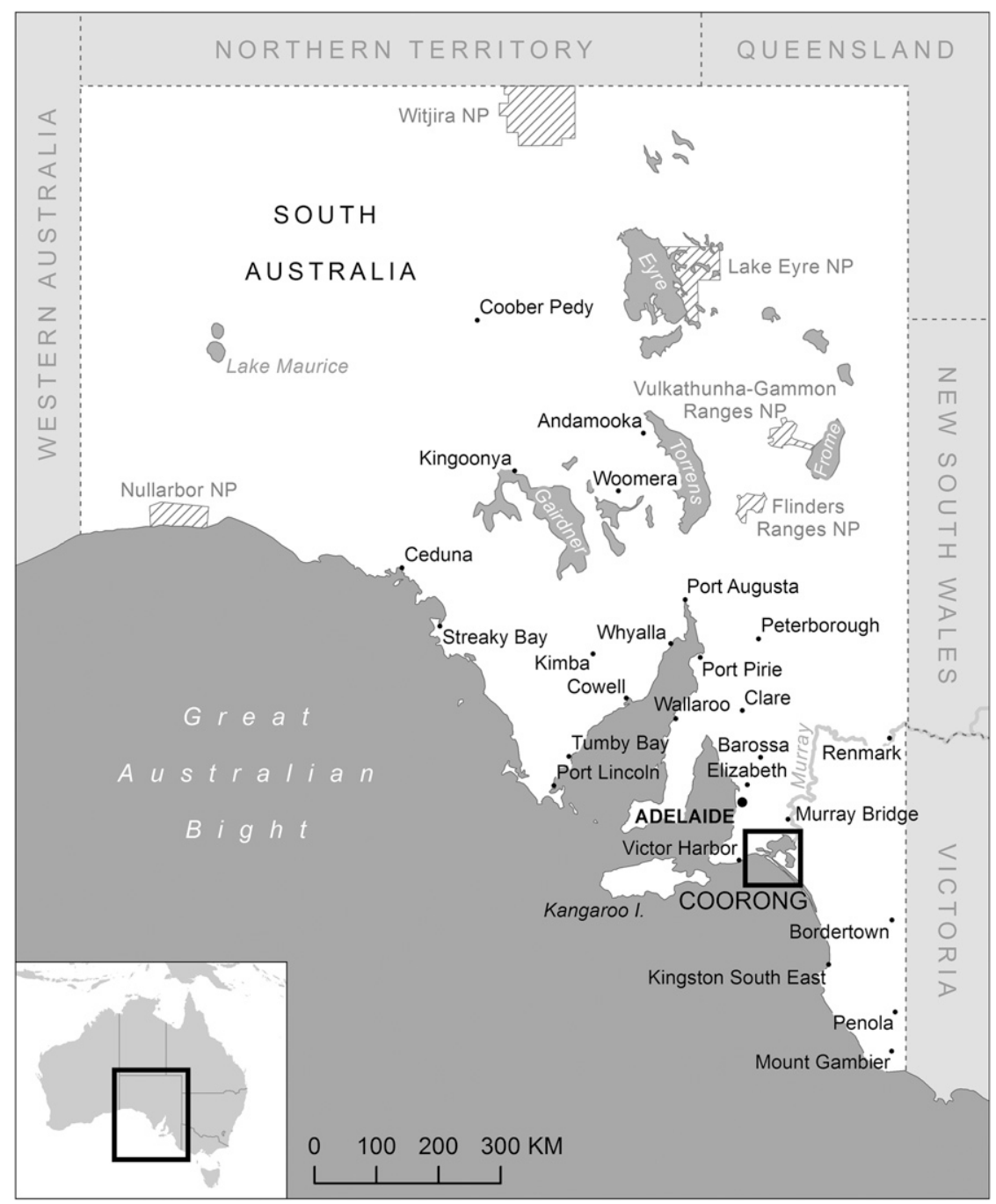

FIG. 1. Map of South Australia showing the location of the Coorong (source: Natural Earth).

reliability that they would require. Indeed, in a separate study, O'Connor et al. (2005) found that forecast skill is not the key issue, as water managers who find forecasts reliable are no more likely to use them than those who do not.

Our original case studies in California, the Pacific Northwest, and metropolitan Washington, D.C., identified further institutional reasons behind managers' reluctance to use the forecasts. These included

- traditional reliance on large built infrastructure,

- organizational conservatism and complexity,

- mismatch of temporal and spatial scales of forecasts to management needs,

- political disincentives to innovation, and

- regulatory constraints.

The U.S. research concluded that wider acceptance of the forecasts would depend on their being incorporated in existing organizational routines, such as river-flow forecasts and demand forecasting, sometimes in ways that are opaque to outside users or even higher organizational levels. Some more recent studies have found positive signs of seasonal-forecast adoption in the water sector where in-house technical capacity is strong (e.g., Bolson and Broad 2013). Adoption has also been facilitated where there are high levels of interaction among producers and users (Kirchhoff 2013).

Interviewees in our original study had suggested that the process of incorporation would take "about 15 years," although they offered no consistent justification for this number, which seemed to be a guesstimate based on expectations of improvement in the forecasts and personal experience of innovation in the sector. Hence, the present study was one of a series of follow-up projects in the United States (Lach and Rayner 2017), 
United Kingdom (Lopez and Haines 2017), Kenya (Haines et al. 2017), and Belize as well as Australia, some 15 years after the original U.S. research. The new study not only expanded the geographical range of the original work, but also its scope. It includes weather and climate information ranging from real-time weather monitoring, through 7-day forecasts, to 3-month seasonal outlooks, to long-term (up to 100 years) climate change projections.

\section{Methodology}

The present study was executed over 4 months in November 2013-February 2014. Semistructured interviews (Spradley 1979) were conducted with a cross section of just over 70 individuals, mostly in Adelaide and its environs, but also with the Australian Bureau of Meteorology (BoM) in Melbourne and at the offices of the BoM and the Murray-Darling Basin Authority in Canberra.

Sampling was nonrandom, also described as theoretical (Glaser and Strauss 1967; Agar 1980) or purposeful (Kuzel 1992) sampling. With the assistance of an informant with extensive experience in the sector, individuals were identified as working in key roles in diverse organizations that currently use, or potentially could use, weather and climate information in the course of their decision-making. Interviewees included

- weather and climate forecasters (7),

- streamflow and groundwater modelers/forecasters (6),

- State and Commonwealth (federal government) river operators (6),

- environmental protection and planning staff (8),

- water regulators (6),

- water allocation planners (9),

- municipal drinking-water and wastewater managers (8),

- emergency services personnel (5),

- irrigators-infrastructure operators and grape, stonefruit, and almond producers (8),

- city managers (2),

- indigenous peoples (3),

- water traders (2), and

- researchers (4).

Although dryland farming is practiced in other parts of the state and there is significant demand for water in mining operations in the desert regions to the north, these sectors were not included in the sample.

The interviews were conducted using a semistructured protocol covering organizational priorities, decisionmaking processes, weather and climate sensitivities, and the awareness and use of forecast information. Transcripts of the interviews were prepared for qualitative thematic analysis, using iterative reading and memos to identify and cross-check material relating to respondents' perceptions and experiences of forecasts on all three time scales. Interview questions addressed the following:

- What kinds of weather and climate information are available?

- What kinds of information (including non-weather and non-climate information) are currently being used in decision-making and how?

- What is the sensitivity of decisions to changes in weather and climate information? That is, what is the potential for information to change decisions?

- What are the institutional and organizational factors that affect the framing and use of weather and climate information?

- How can societal and environmental outcomes of resource management be improved through better use of weather and climate information?

Interviewees were asked to describe their organization and their role within it before being invited to comment on the availability and value of weather and climate information for both current operations and longer-term planning. The intention was to identify the performative dimensions of their decision-making in addition to the more direct "technology-adoption" paradigm (Roncoli 2006), although the focus of this paper remains largely in the second mode.

Interviewees also provided documents, including copies of forecast materials, published reports, PowerPoint presentations, copies of legislation and regulations, and examples of monitoring and reporting paperwork, to supplement or illustrate the information given in interviews. Two workshops were also attended, in which communication of weather and climate science was the central issue.

\section{Complexity: Infrastructure and institutions}

South Australia is the downstream state of the MurrayDarling river system, which spans four states and has a catchment area covering nearly $14 \%$ of the total land area of Australia. Its many reservoirs and dams are all upstream of South Australia in Victoria and New South Wales. Primary production (horticulture, livestock, and dairy) accounts for $75 \%$ of the state's abstraction from the Murray (Mooney and Tan 2012).

This research focuses on the southeast of the state, which is both the most populous part and that which is also responsible for the most water-intensive agriculture, viticulture, and production of fruit and nuts. Agriculture is an important economic activity for the state, which is responsible for over half of Australia's wine production. 
The 2004 Natural Resource Management Act established the basis for controls of almost all water abstraction and use throughout South Australia. The act separates agricultural water rights from land ownership and gives the Minister of Water, Environment and Natural Resources, in consultation with the community, the power to "prescribe" any surface water (farm dams), creeks, rivers, and groundwater aquifers. Once prescribed, any water taken for consumptive (i.e., nonenvironmental) purposes requires a license and is subject to quantitative regulatory controls, unless otherwise exempted.

The act also established eight Natural Resource Management Boards (NRMBs), which are required to produce 10 -yr water allocation plans for their region. These plans are based on modeling of historic streamflow, aquifer, and groundwater data rather than forecast information. At the time this study was conducted, some 22 plans were in operation and 3 more were in preparation.

This institutional complexity is matched by a complex infrastructure for water distribution to those Murray River farmers who cannot abstract water directly from the Murray. Irrigation trusts, such as the Central Irrigation Trust, Renmark Irrigation Trust, and Barossa Infrastructure, provide farmers and domestic customers with Murray River water through pipeline systems supplying thousands of hectares.

Domestic water supply is equally complex, and the imperatives to secure supply became increasingly apparent throughout the Millennium Drought. SA Water is a parastatal company managing 16 reservoirs, 30 water treatment plants, 26 wastewater treatment plants, and, during the drought, added 2 controversial desalinization plants that have required significant reconfiguration of the pipeline system to pump water up from sea level to reservoirs. Electricity costs for pumping water are a major factor in operations decisions.

SA Water also collaborates with various municipal governments in the Adelaide metropolitan region in the development and operation of storm-water harvesting and reuse infrastructure, including wetlands and aquifer recharge designed to conserve potable water that would otherwise be used for irrigation. Recycled water from sewage treatment in Noarlunga and the City of Onkaparinga, immediately south of Adelaide, similarly provides irrigation supply to the nearby McLaren Vale wine-growing district.

The water resources of the Murray-Darling basin, both within the state and upstream, are controlled by the Murray-Darling Basin Authority (MDBA), established by the federal government in 2007. Its role is to promote and coordinate effective planning and management for the equitable, efficient, and sustainable use of the water and other natural resources within the catchment (http:// www.mdba.gov.au). Vested with control over river flows and storage, the MDBA is a complex institution, including the Commonwealth Water Minister and representatives of the basin states (see Fig. 2). The MDBA is required to produce a Basin Plan to provide a coordinated approach to water use and maintain environmental flows across the basin's four states and the Australian Capital Territory (http://www.mdba.gov.au/what-we-do/ basin-plan). Additional environmental flows are managed by the federal government through the Commonwealth Environmental Water Holder (CEWH), who secures water through direct buybacks from irrigators and infrastructure upgrades.

The Basin Plan remains highly controversial, with different interest groups and stakeholders (especially irrigators and environmentalists) putting forward a range of competing views. The draft plan was publicly burned by angry irrigators, while environmentalists claimed that it provided insufficient information to ensure sufficient flows to safeguard vegetation, fish, and wildlife along the Murray River (e.g., Cosier et al. 2011). Subsequent to the fieldwork, a State-appointed Royal Commission received evidence questioning the science behind the plan and legality of its operation, while the Commonwealth government barred federal employees (including MDBA staff) from giving evidence to the Commission (Briggs and Puddy 2018). Controversy over the plan continues to reflect the ongoing tensions between environmental and consumptive needs, which are extremely difficult to balance operationally.

The Murray reaches the sea through the Lower Lakes and Coorong wetlands (Fig. 3). Barrages near the Murray mouth have effectively converted the estuary to a freshwater system. The barrage management system is currently being questioned due to problems of salinity and acid sulfate soils (Kingsford et al. 2011). The area is a Ramsar site and has also been the subject of considerable tension between the State and the indigenous Ngarrindjeri, who call for closer attention to humanity's life-sustaining connections with the river and estuary to promote a focus on rivers as a source of water and of life, rather than focusing only on consumption (Weir 2008).

Hence, the institutional arrangements for waterresource management are extraordinarily complex by any standard. The separation of water rights from land, the system of multiple permissions required before water can be used, and water trading were introduced in the context of the shifting management regime of the Murray-Darling basin over the course of the past decade. These changes sit alongside extensive infrastructure and technological innovations in a complex, multilevel institutional system designed to ensure security 


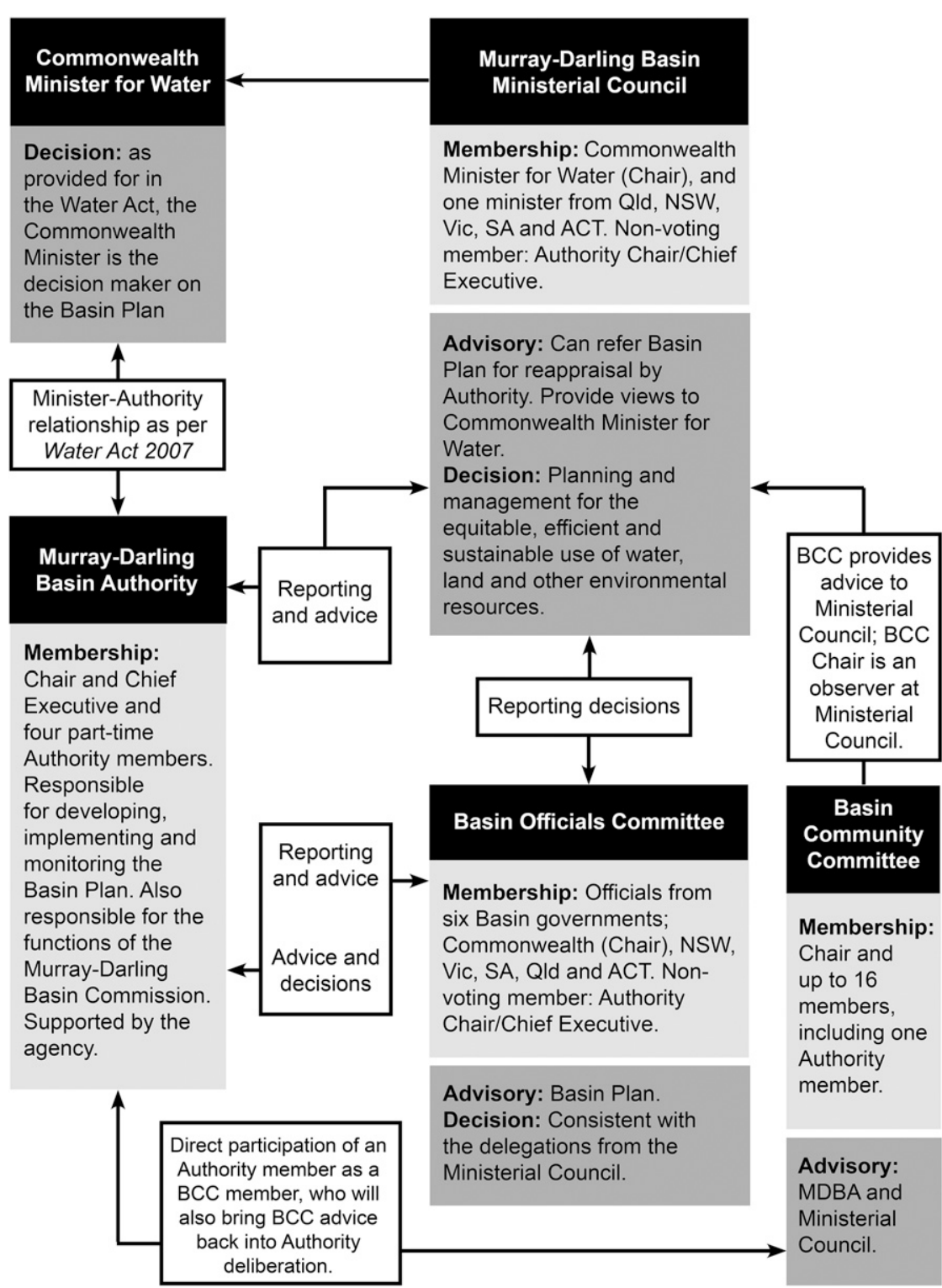

FIG. 2. MDBA Governance Structure (adapted from https://www.mdba.gov.au/about-us/ governance).

of supply and water quality for essential human needs and agriculture as well as those of the environment and indigenous culture. Such complexity inevitably leads to a highly constrained context for decision-making and incorporation of new information.

\section{Sources and uses of weather and climate information}

Departing only slightly from the conventional separation of weather and climate information into short, medium, and long term (Ziervogel et al. 2010), interviewee responses are summarized here according to four time scales on which such information is produced and presented. These are real-time monitoring and sameday forecasts, daily to weekly weather forecasts, seasonal outlooks, and long-term climate change.

\section{a. Real-time information and same-day forecasts}

Within the complex framework of freshwater management there is extensive and expanding provision of real-time monitoring of weather and weather-related phenomena, including streamflow, evapotranspiration, and soil moisture. Much of this information is derived from weather stations operated by the BoM, but also by the NRMBs and some local government authorities. 


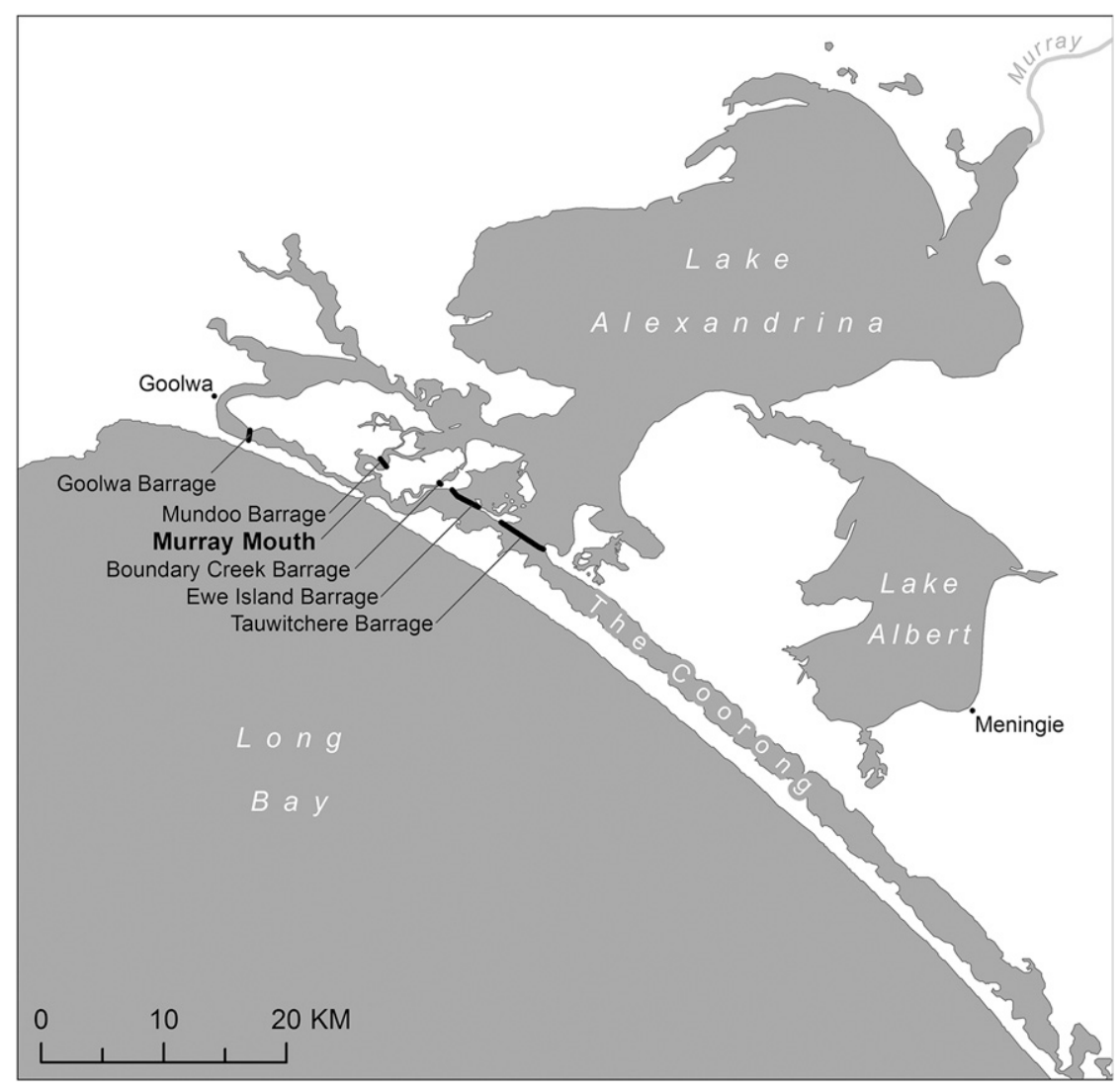

FIG. 3. Map of the Coorong (source: OpenStreetMap).

Real-time data are available at 30-min intervals via the Internet and mobile phones. Some major agricultural operations also maintain their own weather stations.

The experience of the Millennium Drought (19962011) accelerated the adoption of drip irrigation throughout the region. This permits water and added nutrients to be targeted directly at the roots of the plant, reducing runoff and evaporation losses. This, in turn, has promoted the adoption of real-time soil moisture monitoring technology and telemetry, which allows upto-the-minute information to be accessed by farmers, often using mobile phone apps. Grape growers and orchardists use this real-time data to manage dripirrigation systems to ensure the most efficient and highest value use of their water.

Due to the size of the system and the existence of upstream impoundments, flood managers are confident of getting plenty of advanced warning of excess flow in the Murray. Thus, they are principally concerned with heavy downpours causing flash flooding in smaller catchments. Local government storm-water managers, such as those at the City of Onkaparinga, have access to upstream NRMB stream gauges so that they can monitor flows coming into their facilities in more-or-less real time. The same operatives manage sluices to control water flows in urban storm-water harvesting projects through real-time visual inspection of conditions in the water course.

Drinking water quality is also a vital concern. Indeed, unlike their U.S. counterparts in our original study, SA Water managers rated quality concerns above security of supply, their worst nightmare being a boil-water order from the health department. However, SA Water does share the desire of its U.S. counterparts to maintain as low a public profile as possible, and invisibility is a sign of success (Rayner et al. 2005). It is not entirely clear why compromised quality is viewed as worse than interrupted supply in SA, but it may be due to differences in public expectations arising from higher awareness of the realities of water scarcity among South Australians than among Americans, especially in light of the experience of the Millennium Drought.

To ensure the high quality of delivered water, the company is developing an Aquatic Real-Time Monitoring System for the water quality in its reservoirs. Real-time monitoring of current water quality conditions, supplemented by input from BoM 7-day weather forecasts (see below), provides input to decisions such as 
the selection of the off-take height to extract the bestquality water quality in the reservoir water column or to dose the supply with alum and/or activated carbon if there is a potential taste or odor threat from algal growth. Operators can also decide to blend reservoir supplies with Murray River water, for example, if current conditions suggest that cryptosporidium risks are high. Traditionally, these kinds of decisions have depended on the observational craft skills of field operators in real time.

In sum, real-time and near-real-time information combined with new technology provides farmers with a high degree of control over a scarce resource and reduces demand, especially during extreme heat events or water shortage. It is also important to flood management and the maintenance of drinking-water quality. Thus, this kind of information offers improved resilience to vulnerability and enables decision-makers to demonstrate their competence.

\section{b. 7-day weather forecasts}

The principal source of weather forecasts is the BoM, which provides predictions up to 7 days, with most reliance being placed on the first 3 days. The forecasts are numerical weather predictions (NWPs) derived by running what forecasters referred to in interviews as a "poor-man's ensemble" of nine different computer models for the same period. ${ }^{1}$ The logic of this is that the average of several models' predictions is likely to be more reliable over time than any single model.

As noted by Roncoli (2006), user notions of trustworthiness are crucial in their assessments of the credibility and accuracy of forecasts. It was clear from interviews that the BoM enjoys very high credibility for its forecasting capabilities across all sectors. However, agricultural users often also access private weather forecasts, notably WillyWeather and Elders. Users of these forecasts said that they knew that the private forecasters used BoM data, but they preferred specific aspects of the presentation and graphic display of information by the private services. Representation of wind data was often mentioned in this respect, which is especially important to decisions about when to apply sprays to crops, including fungicides and dormancy breakers.

\footnotetext{
${ }^{1}$ The nine models are those of the Australian Bureau of Meteorology (2), U.S. National Oceanographic and Atmospheric Administration, U.K. Met Office, Japan Meteorological Agency, European Centre for Medium-Range Weather Forecasts (2), Meteorological Service of Canada, and Germany's National Weather Service (Deutscher Wetterdienst).
}

BoM forecasts of extreme heat events are also valued by grape growers and orchardists as they allow them to increase irrigation to vines and trees a few days in advance to increase their ability to withstand such adverse conditions. Interviewees generally expressed satisfaction that 7-day forecasts were perfectly adequate for these purposes.

Local flood-management and storm-water-harvesting operations also make extensive use of near-term weather forecasts, reviewed daily over the Internet. The BoM operates a flood warning system, which had recently been upgraded to improve lead times (it now makes use of rainfall and streamflow observations, NWPs, and hydrologic models). The BoM is legally required to provide specific flood warnings for major catchments, such as the Onkaparinga River, which are faxed or emailed to local flood managers, usually 3 or 4 days out. However, as noted above, local-government managers have to deal with minor catchments largely based on real-time NRMB streamflow data.

SA Water relies on BoM weather forecasts as input to the in-house model that it uses for balancing water supply and demand. This model relies directly on the BoM forecast for the next 7 days and then selects from the historical record the conditions that have followed that 7-day pattern in the past to create a prediction of demand and availability for the next 14 days. Along with electricity prices (which can peak at AU $\$ 13,000 \mathrm{MWh}^{-1}$ ), this is used to direct the company's pumping schedule for the following $48 \mathrm{~h}$. The objective is to manage the water supply network to keep the reservoirs as full as possible at the lowest possible power prices.

The MDBA's Murray River operators, based in Canberra, make decisions about when to release water from upstream impoundments to supply the demands of downstream users with water allocations and to control flooding on the river. MDBA operators pay close attention to BoM weather forecasts in 3-h time steps over the coming 4 days and daily steps for 4 days after that. This choice of time interval is driven by the availability of the forecasts and the operators' perception that, in their own words, beyond a week "the forecast becomes just not good enough."

From the South Australian standpoint, the MDBA operators' role is to deliver the state's flow entitlement to the border. Within the state, operations are the responsibility of the Department of Environment and Water (DEW), ${ }^{2}$ which externally coordinates the state's

\footnotetext{
${ }^{2}$ At the time of fieldwork, this was the Department of Environment, Water and Natural Resources (DEWNR); the name was changed in March 2018.
} 


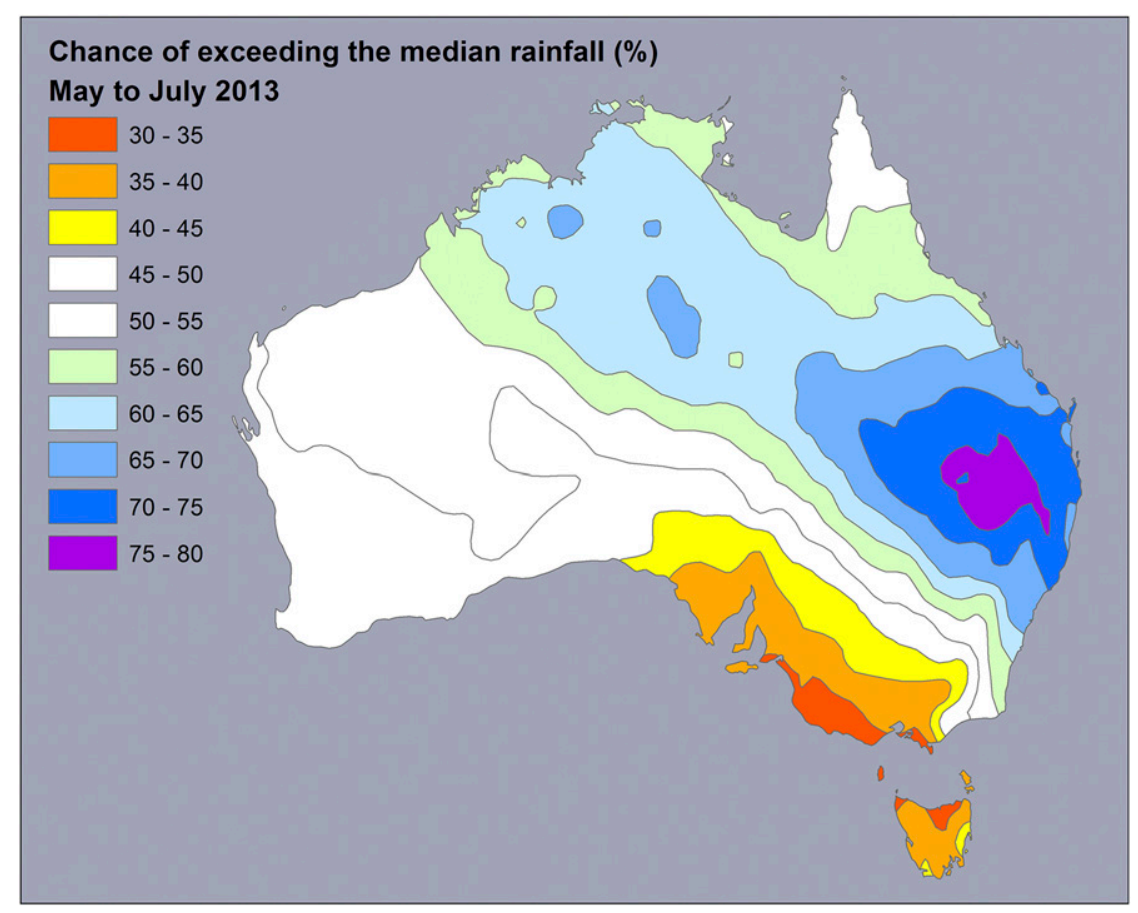

FIG. 4. Example of a 3-month rainfall outlook for Australia (source: Bureau of Meteorology, Australian Government).

needs with the MDBA. DEW also works in partnership with SA Water to manage the locks and barrages that control river flows and environmental watering within the state. DEW's river operators make extensive use of BoM and WillyWeather 7-day forecasting, paying particular attention to evaporation levels, and wind speed and direction in the Lower Lakes, where the combination of freshwater pulses and wind are used to flush Lake Albert, which has no downstream outlet of its own, and where operators are also managing freshwater releases into the Coorong (Fig. 3). The BoM also produces a range of bespoke products for other agencies and industries, both private and public, including aviation and the mass media.

Overall, consistent with earlier findings in the United States, interviews with decision-makers in all watermanagement sectors saw weather forecasts up to 7 days as adequate for most operational purposes. Spatial specificity seemed to be valued more than extended time horizons.

\section{c. Seasonal outlooks}

The BoM has operated a seasonal climate prediction service since 1989 , with a focus on rainfall and temperature. In May 2013, the BoM changed the basis for its seasonal outlooks from statistical modeling of historical climatology to dynamic predictive climate modeling.
Seasonal outlooks are posted on the Internet, in the form of graphics representing percentage probabilities that conditions will deviate from the median, as shown for rainfall in Fig. 4.

Consistent with the findings of Crane et al. (2010) in Georgia, United States, SA irrigators mostly refer to the seasonal outlooks only as background information or context for the short-term weather forecasts on which they principally rely. A typical irrigator's response was, "We do (look at seasonal outlooks) but I haven't found them to be terribly accurate, especially when it comes to things like rainfall. Quite often we've heard early in the season it's going to be terribly dry and will finally get a large amount of summer rainfall or vice versa. So we do not as yet have a lot of faith-we can look at general trends but unfortunately we are a little bit more micro when we're looking in terms of accuracy."

At first sight this seems to confirm the findings of earlier nationwide surveys of Australian farmers conducted in 2001 and 2002, which found that $76 \%$ of the sample offered "forecasting is not reliable" as the primary reason for not using seasonal outlooks (Hayman et al. 2007). However, as was the case in earlier research in the United States (Rayner et al. 2005), few of the farmers were able to offer a clear idea of what would constitute adequate reliability for their purposes. Furthermore, it was not clear that the farmers would be 
able to make greater use of seasonal forecasts, even if they were demonstrated to be more reliable as the time scale of such forecasts does not fit well with that of farm operations, especially in light of the widespread adoption of drip irrigation and the current operation of the water market.

Addressing the wider Australian context, Hayman et al. (2007, p. 975) argue that "Farmers are likely to use seasonal forecasts (SCFs) if they perceive decision making with climate uncertainty as a problem and that SCFs provide information in a timely and useful format that reduces this problem." In SA, the adoption of drip irrigation seems to offer efficiencies utilizing real-time and near-term information that significantly reduce the vulnerability of farmers (and drinking water suppliers) to seasonal variability. Similarly, the reforms in water licensing, leading to the development of an active water market, have also greatly increased the ability of viticulturists and orchardists to ensure the viability of vines and trees during dry periods by buying water from other users, such as growers of annual crops whose value may be less than the price that the farmer can obtain by selling all or part of his allocation. In this situation, the relative value of seasonal forecasts and real-time to near-term information may potentially be quite different for grape growers versus farmers of annual crops. A dry seasonal forecast may encourage the latter to refrain from planting or to sacrifice a crop. Viticulturists and orchardists cannot exercise the sacrifice option as trees and vines must be kept alive from year to year. This means using real-time and near-term forecasts to make the best use of whatever water is available.

Several interviewees suggested that water trading had been important in enabling them to survive the Millennium Drought. Agriculturalists and state officials credited the ability to trade water entitlements and/or allocations as having greatly enhanced the ability of South Australian farmers to maintain irrigated agriculture even though, at times, prices rose as high as a staggering AU $\$ 18,000 \mathrm{ML}^{-1}$. Water markets are at an early stage of development and, as yet, traders do not seem to place much reliance on seasonal outlooks. However, there was a clear sense that there is potential for a futures market in water to develop and that this would be likely to be influenced by the seasonal climate outlooks, especially if forecasting skill could be shown to improve.

In addition to the seasonal climate outlooks, the BoM also produces seasonal flood and streamflow forecasts for all of Australia. Maps available on the BoM website (http://www.bom.gov.au) present these forecasts (for limited areas) using pie charts to communicate probability and skill level. The BoM is developing a streamflow forecasting approach that will merge statistical data with dynamical modeling using the same model that it uses for seasonal climate outlooks. However, while local storm-water harvesting and flood management officials pay close attention to weather forecasts, and refer to long-term climate forecasts to justify infrastructure planning, they reported that they currently have little use for seasonal outlooks other than as "general background." Flash flooding during heavy downpours is of greatest concern and most likely to lead to serious losses. However, managers saw the forecasting imperative here as improving the spatial scale of 4-day and the skill of 7-day forecasts, rather than improving seasonal prediction.

MDBA river operators run a statistical streamflow model for the river system referred to as Big Mod. Operators select historical data comparable to current-year measurements of median flows in the basin to predict water availability over the rest of the year. This method seems to provide a level of information that operators are comfortable is adequate for their decision-making and have not seen any reason to vary the procedure by, for example, running the model using seasonal climate predictions of El Niño or La Niña conditions to select samples of such years. However, operators do pay attention to seasonal outlooks and were one of the few groups interviewed who were aware of the recent shift from a statistical to a probabilistic approach in the modeling underlying the outlooks. However, they described the seasonal outlooks as "one of our primary background tools.... It's one of a range of factors. It's definitely something you look at but it's not quantitative." River operations ultimately depend on the operators' judgment and craft skill using a diverse range of inputs.

DEW river operators report making more extensive and direct use of the BoM seasonal outlooks than do their counterparts in the MDBA, particularly the monthly updates of the rainfall forecasts and the seasonal streamflow forecasts. They described the seasonal climate outlooks as "getting better and better," especially since the shift from statistical to probabilistic modeling.

A scientist at the government's South Australian Research and Development Institute (SARDI), who is responsible for monitoring the ecological condition of the Murray River, accesses the BoM's seasonal forecasts as input to long-term scheduling of sampling of the biota under various flow conditions. However, nearer the date, actual sampling activity is determined by flow forecasts from the MDBA that are based on historical data and on actual weekly measurements from the WaterConnect section of DEW's website. 
In sum, awareness of seasonal projections among water managers and users in SA is much higher than in our U.S. study of $15+$ years ago, and they are beginning to be incorporated in other information products. Potentially, they could become significant inputs into decision-making in emergent water markets. But, as yet, their use is confined to defining possibility spaces for decision-making rather than the basis for action.

\section{d. Climate change models}

Moving from seasonal outlooks to multidecadal climate predictions, the BoM has collaborated with the Commonwealth Scientific and Industrial Research Organization (CSIRO) and various universities in the joint development of the Australian Community Climate and Earth System Simulator (ACCESS), which is a coupled climate and Earth system model (Plummer et al. 2009). Operational since August 2010, ACCESS provides information about long-term climate change to researchers and policy-makers. Results from running ACCESS tend to be incorporated in wider-ranging expert reports on climate change and its implications, rather than being communicated directly as forecasts.

Over the past decade, the City of Adelaide and other local authorities in the metropolitan region have been engaged in extensive efforts to understand and plan for the impacts of climate change in their jurisdictions, particularly water security, sea level rise, and extreme weather events. Much of this is based on climate change scenarios generated by consultants and expert panels drawing on IPCC scenarios and CSIRO climate modeling.

A set of downscaled climate projections for the Onkaparinga basin has been developed by the Goyder Institute, which has funded and coordinated major work downscaling climate models for water planning in the state drawing on the subset of the GCMs used by the IPCC that best reproduce the state's climate drivers, such as the Indian Ocean dipole and El Niño-Southern Oscillation. The Institute is acknowledged as having played a critical role in providing the SA Government with scientific advice in negotiating the Murray-Darling Basin Plan with Victoria, New South Wales, and the Commonwealth. This was largely based on historical rather than probabilistic modeling. The newer downscaled climate projections seem to be driven from a predominately scientific perspective rather than a decision-maker one. The challenges of identifying what is policy-relevant and conveying it to decision-makers was evident at a Goyder Institute workshop attended during the study.

The workshop audience consisted of a cross section of SA government officials drawn from agencies for which climate change would be most likely to be relevant, either as a forcing factor or because of the potential influence of climate impacts on their activities. The proceedings consisted of $2 \mathrm{~h}$ of back-to-back technical presentations from modelers, introduced with justifiable pride in the impact factor of the scientific journal in which the work was published. There was no opportunity for questions and answers until after all of the presentations were complete, at which point the somewhat baffled decision-maker audience was invited to suggest how the work might be useful to them. It is fair to say that the agency officials struggled to identify concrete applications for the information. In the words of one government participant, "As an end user... there does not seem to be a methodology where you're actually brought in from the point of inception and actually participating in the research."

It was suggested that communication of the demonstrably high-quality science might have been more effective had the scientists started by asking the policymakers to identify where climate change predictions might affect their decision-making or operations and then iterating on the most relevant aspects of the predictions, rather than asking policy-makers to digest the full range of predictions with which they were presented. As noted by Crane et al. (2010, p. 56), "user participation in defining the research agenda and in developing and testing decision support tools will ensure that the latter have a higher degree of salience, credibility, legitimacy, and consequently a greater chance of impacting real-life decisions."

While the organizers welcomed this suggestion, it is not apparent that it has had much impact on subsequent practice. Scientists involved in these projects expressed some reticence about being seen to stray into making policy recommendations. As one said of the relation between the scientists and policymakers, "Well I guess our role was to provide that science evidence to inform policy makers, but for the policy makers to write their own policy. So, it was very separate. We weren't engaged and I guess that the philosophy is that we'll provide the scientific evidence, the scientific base. We won't be drafting the policy." These concerns highlight the tension between developing usable knowledge in a process of coproduction (Jasanoff and Wynne 1998) with policy-makers, and the danger of being seen to be straying into what Pielke (2007) calls "stealth advocacy," which the scientists clearly and properly wished to avoid.

However, such tensions are not necessarily insurmountable, and elsewhere in SA coproduction of information by technical experts and potential users does seem to generate usable knowledge. For instance, 
a more iterative approach, involving decision-makers from the inception of the investigation, has been undertaken through the establishment of partnerships led by DEW under the South Australian Climate Change Adaptation Framework. This program cut across state government departments and aligned with the NRMBs and the Commonwealth-supported regional economic development bodies across the state to promote climate change awareness and adaptation planning in South Australia. The program proved effective in promoting community awareness of the time scales on which critical adaptive decisions will have to be made in the future. However, they did not make use of downscaled climate models. In the words of a senior DEW official, "Typically, the Climate Change Partnerships start with broad, rough, long-term indicators of where climate is likely to be heading over a 50- to 70-year period, typically derived from IPCC AR 4 and the standard 3 models and the rough trends.... No downscaling, just general trends and so that for them it's enough to run through the decision pathway set."

The decision pathways are derived by developing timelines of when critical decisions about infrastructure replacement or development would have to be made and subsequently exploring which options for doing so are likely to be most resilient. In the words of the same official, "Coming to terms with the length of time of a decision challenges just how much climate information you really need...there's very few decisions that need very good climate information." Having said that, the same interviewee argued that it was important that both the Commonwealth and State adopt the Goyder Institute downscaled projections to ensure that decision-makers are not confused by multiple sets of numbers, even though the differences between them are less important for policy-making than recognition of the general trend toward a "warmer, drier future."

SA Water does use downscaled climate models from CSIRO and the Goyder Institute for infrastructure planning for the 2030-70 timeframe. As one executive stated, "We take the view that even 2030 is getting to the outside end of the long-term planning phase for investment in the water industry... . I guess we always like to present a long-term view. But we've shied away from using the 2100." According to SA Water's operations and maintenance subcontractor, long-term infrastructure planning largely consists of evaluating and extending options for interbasin water transfers to enhance the flexibility of the system and the ability to deploy the desalinization plants, rather than adding new storage as the options for storage are, to put it mildly, seriously constrained.
Among city managers and agricultural water users there was little skepticism that climate change is real. However, almost none of those interviewed made any direct use of long-term climate change predictions. There appear to be several reasons for this:

1) Several interviewees suggested that the legal requirements for updating water allocation plans and the Murray-Darling Basin Plan every 10 years represented opportunities to tune water resource management practices in response to emerging climate trends, especially in the absence of major new infrastructure options on the Murray that might otherwise require longer-term planning.

2) Experience of the drought and the reorganization of water rights over the past decade had promoted the confidence of some agricultural water users in their ability to adapt to changing conditions.

3) There was a strong sense among irrigators that climate was a relatively minor factor in their decisionmaking relative to factors such as commodity prices in international markets and the strength of the Australian dollar. They saw their ability to shift to more drought resistant cultivars, etc., as constrained by consumer demand for particular varieties as mediated by supermarket chains in Britain and the United States.

This last point emphasizes the importance of factoring the extent of freedom for changing decisions and practices into any assessment of the usefulness of weather and climate information to decision-makers.

\section{Discussion and conclusions}

In the complex institutional and infrastructural context of South Australia, weather and climate information is likely to be explicitly incorporated in decision-making when decision-makers see it as having the potential to contribute to the satisfactory performance of their organizational roles. As we observed in our earlier study in the United States, "integration of new information... is a challenge of articulating that information within an organization's frameworks of meanings and collective action, not merely a problem of removing exogenous barriers to information" (Rayner et al. 2005, p. 224). Measures of success in their organizational roles vary among SA water managers and users. Consistent with our earlier findings elsewhere, those involved in delivering services to the general public, such as drinking-water supply, sewage management, and flood control, are largely unanimous in defining success in terms of their ability to maintain a low profile in the media and minimizing the number of complaints about the quality of 
service. This view is also common among irrigation-water infrastructure operators serving farmers. Among farmers, success is measured by their ability to sustain profitable operations from year to year, especially under stressful conditions. The extent to which weather and climate information is aligned with these goals is likely to be a significant determinant of its incorporation into decisionmaking, although all of these sectors are likely to be cautious innovators rather than early adopters (Rogers 2003). This is consistent with what we learned from water company managers in the United Kingdom (Lopez and Haines 2017), for whom professional risk aversion and regulatory arrangements do not incentivize using probabilistic weather forecasts for high-stakes drought management decisions, even when this could-in principleincrease efficiency in a long-term/statistical sense. However, this kind of information can be incorporated into lower-stakes decisions such as optimizing pumping schedules when resources are "healthy"-indicating that different decision contexts and stakes are also influential for the uptake of forecast information.

Like their American counterparts, SA water managers rely on large built infrastructure, including the upstream dams on the Murray in Victoria and New South Wales, the networks for pipes operated by irrigation districts, SA Water's reservoirs and investments in desalinization infrastructure, and the barrages protecting the Lower Lakes. However, this conservative approach to infrastructure has been accompanied by institutional innovation by both the Commonwealth in reforming the management of the Murray River and the State in reforming its regulation of water use within its borders. Both sets of reforms are designed to direct water to both environmental and highest-value consumptive use. However, the allocation of Murray River water between these uses remains a hotly contested political issue around which water managers need to tread carefully.

It has long been recognized that farmers think in terms of shorter timeframes and more localized scales than the long-term global perspective of scientists (Hansen et al. 2004; Roncoli 2006). The research reported here not only confirms this finding among irrigators, but found that decision-makers across several sectors expressed greater interest in the expansion of localized real-time monitoring than extending the skill of seasonal forecasting. This focus on real-time information is made possible, in part, by inexpensive instrumentation, for example, measuring soil moisture, and the explosive growth in information and communications technology (ICT) capacity to communicate such information via mobile phones and the Internet. The focus on real-time is consistent with the finding of Bolson et al. (2013) in the United States, that many water managers expressed more interest in better monitoring information than predictions. This shortterm focus is accompanied by a demand for information at finer geographical scales, which is only partly met by the $6 \mathrm{~km} \times 6 \mathrm{~km}$ grid scale of the BoM forecasting technology. Technological innovation has contributed to resilience both in the flood control and the configuration and management of domestic water supplies. In the agricultural sector, extended drought conditions have driven the shift to drip irrigation, efficient operation of which relies on real-time measurements of soil moisture. Easy access to hourly and daily information has enabled managers to integrate this information into organizational routines. An exception to this real-time focus in agriculture is farmers of annual crops (e.g., grains), who might, in the expectation of an exceptionally dry year, decide to forgo planting in favor of selling their annual water allocation to orchardists and grape growers at top dollar.

The most extensive use of probabilistic weather forecasts is looking 3-7 days ahead. Consistent with the findings of our earlier U.S. study, these were considered to be adequate for most operational purposes in all sectors. Furthermore, the strongest desire for improvements in information was for extension of accurate weather forecasts out to 10 days, or even a little more, rather than the 90-day projections of the seasonal outlooks.

With regard to the acceptance of seasonal outlooks, there seems to have been significant progress over the decade since Ritchie et al. (2004, p. 553) concluded that, "Although the ability to forecast climatic variability has progressed significantly in recent years, there appears to be little use of seasonal climate forecast information in catchment water management decision-making." Consistent with the prediction of 15 years ago (Rayner et al. 2005), seasonal climate information is beginning to be incorporated into sector-specific decision-support tools alongside other relevant variables. The increased use is represented both by recognized improvements in the technical performance of the 3-month seasonal outlooks and their visibility to decision-makers. However, almost all interviewees who mentioned these have not seen the kinds of improvements in forecast skill and scale that would make this information easy to integrate into existing decision-making frameworks. They repeatedly emphasized that they largely treat seasonal outlooks as background information or context in which to consider the 7-day weather forecasts or statistical streamflow models, which remain the principal weather and climate inputs into water resource management across all sectors. Agricultural users frequently pointed out that on the seasonal time scale, other kinds of variables, such as 
uncertainty about commodity prices and currency exchange rates, were likely to exert a greater influence on their decision-making than climatic variability.

When weather and climate information is integrated into organizational decision-support tools, it is often difficult for users to identify its institutional and technical provenance. Interviewees in South Australia frequently seemed unsure about which weather or climate model was the source of inputs to the specialized models or predictions that they were using for operational or planning purposes, and there was often considerable ambiguity about whether predictions were statistical or dynamic. However, this may not matter where decisionmakers have high levels of trust that the experts providing the forecasts are both politically independent and technically competent. This certainly seems to be the case with the BoM, which is widely recognized as the original source of forecast information, suggesting that where the institutional provenance is known and trusted the technical details may be less important for potential users.

The use of long-term climate change models by irrigation-water users and other freshwater-resource managers in the southern part of the state remains indirect. The downscaled models provide confirmation of the likelihood that the future climate of SA will be "warmer and drier," and, in this respect, they are regarded similarly to the seasonal outlooks as providing context or background information for adaptation planning, rather than as the basis for specific decisions.

In conclusion, it is apparent that in South Australia, technological and institutional innovations, themselves driven by the Millennium Drought, have radically increased the value accorded to real-time weather and climate information in recent years. While there has been some progress in the skill and the use of seasonal outlooks and extensive efforts at downscaling long-term climate models, these have had less impact on day-to-day management of water resources, largely due to institutional pressures that make it difficult to incorporate such information in existing organizational routines. Under these conditions, there is something of a mismatch between scientific aspirations to improve the skill of seasonal and long-term climate forecasting and the temporal rhythms of decision-making among water managers and users.

Acknowledgments. This research was made possible by generous financial support from the Australia and New Zealand School of Government and the Goyder Institute to Flinders University for the ANZSOGGoyder Institute Visiting Professorship in Public Sector Management and by additional funding from the Oxford Martin School. The author is grateful to Flinders
University for its extraordinary hospitality during the study period and is especially grateful to Stacey Richardson for her superb research and administrative support. Special thanks are also due to Kathryn Bellette for her wisdom and guidance in navigating the institutional landscape of South Australian freshwater management. I am also grateful to Sophie Haines and Michael Gilmont for their perceptive comments on an earlier draft.

\section{REFERENCES}

Agar, M., 1980: The Professional Stranger: An Informal Introduction to Ethnography. Academic Press, 276 pp.

Bolson, J., and K. Broad, 2013: Early adoption of climate information: Lessons learned from South Florida water resource management. Wea. Climate Soc., 5, 266-281, https://doi.org/10.1175/ WCAS-D-12-00002.1.

_ C. Martinez, N. Breuer, and P. Srivastava, 2013: Climate information use among southeast US water managers: Beyond barriers and toward opportunities. Reg. Environ. Change, 13 (Suppl. 1), 141-151, https://doi.org/10.1007/s10113-013-0463-1.

Briggs, C., and R. Puddy, 2018: Murray-Darling royal commission rejects federal attempt to block bureaucrats from giving evidence. ABC News, 18 June, https://www.abc.net.au/news/ 2018-06-18/royal-commission-rejects-federal-attempt-to-blockbureaucrats/9880434.

Broad, K., 2002: Producing and using climate forecasts: Bridging the supply and demand gap in climate forecast production and use. La Niña and Its Impacts: Facts and Speculation, M. Glantz, Ed., United Nations University Press, 246-255.

Callahan, B., E. Miles, and D. Fluharty, 1999: Policy implications of climate forecasts for water resources management in the Pacific Northwest. Policy Sci., 32, 269-293, https://doi.org/10.1023/ A:1004604805647.

Cash, D. W., W. C. Clark, F. Alcock, N. M. Dickson, N. Eckley, D. H. Guston, J. Jager, and R. B. Mitchell, 2003: Knowledge systems for sustainable development. Proc. Natl. Acad. Sci. USA, 100, 8086-8091, https://doi.org/10.1073/pnas.1231332100.

Cosier, P., and Coauthors, 2011: Statement on the $2011 \mathrm{draft}$ Murray-Darling Basin Plan. Wentworth Group of Concerned Scientists, 27 pp., http://wentworthgroup.org/wp-content/ uploads/2013/10/Statement-on-the-2011-Draft-Basin-Plan.pdf.

Crane, T. A., C. Roncoli, J. Paz, N. Breuer, K. Broad, K. T. Ingram, and G. Hoogenboom, 2010: Forecast skill and farmers' skill: Seasonal climate forecasts and agricultural risk management in the Southeastern United States. Wea. Climate Soc., 2, 44-59, https://doi.org/10.1175/2009WCAS1006.1.

Easterling, W. E., and P. C. Stern, Eds., 1999: Making Climate Forecasts Matter. National Academies Press, 192 pp., https:// doi.org/10.17226/6370.

Glaser, B., and A. Strauss, 1967: The Discovery of Grounded Theory: Strategies for Qualitative Research. Weidenfield and Nicolson, 271 pp.

Haines, S., C. Imana, M. Opondo, G. Ouma, and S. Rayner, 2017: Weather and climate knowledge for water security: Institutional roles and relationships in Turkana. REACH Working Paper 5, 22 pp., https://reachwater.org.uk/wp-content/uploads/2017/09/ 2017_10_WorkingPaper_Haines-et-al.pdf.

Hansen, J., S. Marx, and E. Weber, 2004: The role of climate perceptions, expectations and forecasts in farmer decision making: The Argentine Pampas and South Florida. Tech. Rep. 
04-01, International Institute for Climate Prediction, $142 \mathrm{pp}$, https://iri.columbia.edu/ jhansen/RoleOfClimatePerceptions.pdf.

Hayman, P., J. Crean, J. Mullen, and K. Parton, 2007: How do probabilistic climate forecasts compare with other innovations that Australian farmers are encouraged to adopt? Aust. J. Agric. Res., 58, 975-984, https://doi.org/10.1071/AR06200.

Jasanoff, S., and B. Wynne, 1998: Science and decisionmaking. Human Choice and Climate Change, S. Rayner and E. L. Malone, Eds., Battelle Press, 1-87.

Kingsford, R., K. Walker, R. Lester, W. Young, P. Fairweather, J. Sammut, and M. Geddes, 2011: A Ramsar wetland in crisisThe Coorong, Lower Lakes and Murray Mouth, Australia. Mar. Freshwater Res., 62, 255-265, https://doi.org/10.1071/MF09315.

Kirchhoff, C., 2013: Understanding and enhancing climate information use in water management. Climatic Change, 119, 495-509, https://doi.org/10.1007/s10584-013-0703-x.

Kuzel, A. J., 1992: Sampling in qualitative inquiry. Doing Qualitative Research, B. F. Crabtree and W. L. Miller, Eds.,Vol. 3, Research Methods for Primary Care, Sage, 31-44.

Lach, D., and S. Rayner, 2017: Are forecasts still for wimps? J. Southwest, 59, 245-263, https://doi.org/10.1353/jsw.2017.0013.

Lemos, M. C., T. Finan, R. Fox, D. Nelson, and J. Tucker, 2002: The use of seasonal climate forecasting in policymaking: Lessons from Northeast Brazil. Climatic Change, 55, 479-507, https:// doi.org/10.1023/A:1020785826029.

Lopez, A., and S. Haines, 2017: Exploring the usability of probabilistic weather forecasts for water resources decision-making in the United Kingdom. Wea. Climate Soc., 9, 701-715, https://doi.org/ 10.1175/WCAS-D-16-0072.1.

Mooney, C., and P. L. Tan, 2012: South Australia's River Murray: Social and cultural values in water planning. J. Hydrol., 474, 29-37, https://doi.org/10.1016/j.jhydrol.2012.04.010.

O'Connor, R., B. Yarnal, C. Dow, C. Jocoy, and G. Carbone, 2005: Feeling at risk matters: Water managers and the decision to use forecasts. Risk Anal., 25, 1265-1275, https://doi.org/ 10.1111/j.1539-6924.2005.00675.x.
Pielke, R. A., Jr., 1999: Who decides? Forecasts and responsibilities in the 1997 Red River flood. Appl. Behav. Sci. Rev., 7, 83-101, https://doi.org/10.1016/S1068-8595(00)80012-4.

_ 2007: The Honest Broker: Making Sense of Science in Policy and Politics. Cambridge University Press, $188 \mathrm{pp}$.

Plummer, N., and Coauthors, 2009: A seasonal water availability prediction service: Opportunities and challenges. 18th World IMACS Congress and MODSIM09 International Congress on Modelling and Simulation, R. S. Anderssen, R. D. Braddock, and L. T. H. Newham, Eds., Modelling and Simulation Society of Australia and New Zealand/International Association for Mathematics and Computers in Simulation, 80-94, https:// mssanz.org.au/modsim09/Keynote/plummer.pdf.

Rayner, S., D. Lach, and H. Ingram, 2005: Weather forecasts are for wimps: Why water resource managers do not use climate forecasts. Climatic Change, 69, 197-227, https://doi.org/ 10.1007/s10584-005-3148-z.

Ritchie, J. W., C. Zammit, and D. Beal, 2004: Can seasonal climate forecasting assist in catchment water management decisionmaking? A case study of the Border Rivers catchment in Australia. Agric. Ecosyst. Environ., 104, 553-565, https://doi.org/ 10.1016/j.agee.2004.01.029.

Rogers, E. M., 2003: Diffusion of Innovations. 5th ed. Free Press, $576 \mathrm{pp}$.

Roncoli, C., 2006: Ethnographic and participatory approaches to research on farmers' responses to climate predictions. Climate Res., 33, 81-99, https://doi.org/10.3354/cr033081.

Spradley, J. P., 1979: The Ethnographic Interview. Holt, Reinhart and Winston, $247 \mathrm{pp}$.

Weir, J. K., 2008: Connectivity. Aust. Humanit. Rev., 45, http:// australianhumanitiesreview.org/2008/11/01/connectivity/.

Ziervogel, G., P. Johnston, M. Matthew, and P. Mukheibir, 2010: Using climate information for supporting climate change adaptation in water resource management in South Africa. Climatic Change, 103, 537-554, https://doi.org/10.1007/ s10584-009-9771-3. 